\title{
Quantitative Analysis of Debris and Plastic Pollution on Beaches in Northern Madagascar
}

\author{
Emma Gjerdseth*, Economics and Environmental Studies
}

\begin{abstract}
Marine pollution, with the majority originating from land based sources, poses a significant threat to species in marine and coastal ecosystems. By understanding the make-up of the beach debris, more effective and targeted education and awareness programs can be developed to reduce marine pollution originating from land based sources. In this study, beach debris was recorded, quantified and classified, from three mostly sandy beaches in the northern Diana Region of Madagascar. At the time of this study there were no published reports about debris on Malagasy beaches, thus this paper provides original insight into debris composition and distribution in the region. The debris was observed and classified using transect methods and charts developed by the Commonwealth Scientific and Industrial Research Organisation (CSIRO) complimented by visual observations. CSIRO has performed similar studies before, therefore the use of their methods made for easier data collection and allowed for ease of comparison for future studies. The abundance of debris per square metre varied between the beaches, which shows a predicted increase with usage. The beaches that had a high number of observed visitors also had a higher quantity of debris. Plastic debris density remained relatively stable between the beaches. A total of 1216 pieces of debris was recorded, with 758 pieces being of plastic, distributed at an average of 0.158 pieces of debris per square metre and 0.109 pieces of plastic per square metre. The highest total quantity of debris and plastic litter was found at Ramena followed by Ampasindava and Baïe de Sakalava.
\end{abstract}

\section{INTRODUCTION}

Plastics are typically strong, lightweight, and cheap materials with high durability and utility whose usage has increased rapidly over the past three decades (Andrady, 1990; Derraik, 2002; Hanseb, 1990; Laist, 1987). The majority of human-made marine debris is made up of plastic (Reisser et al., 2013), and since their introduction to the consumer market less than 60 years ago they have become an increasingly critical global pollution issue, as well as the most common form of marine debris (Zettler et al., 2013). The global annual production of plastics was estimated at 245 million tons in 2013 (Zettler et al., 2013) and at 280 million tons in 2011 by Reisser et al. (2013) after having increased rapidly from 1.7 million tons in 1950.

\footnotetext{
*Emma graduated cum laude from the University of Oregon in the summer of 2016, with a double major in economics and environmental studies. In the spring semester of 2015 she studied abroad in Madagascar, an experience that had a big impact on her and enabled Emma to do her own academic research for the first time. While abroad Emma conducted research on beach debris to contribute to a limited body of available research, and to learn more about this issue. She is currently back in her home country of Norway studying mathematics at the University of Oslo, hoping to pursue a career in research. Please direct correspondence to emmagjerdseth@gmail.com.
} 
Marine debris is known to affect more than 267 species by entanglement or ingestion, including species such as fish, seabirds, turtles and whales. Plastic marine debris has also been found to cause economic losses, such as in the case of plastic bags blocking water intakes and propellers being entangled in abandoned fishing gear (Allsopp et al., 2006; Sheavly, 2005).

There are two main sources from which plastics end up in the marine environment: rubbish dumped at sea or land-based rubbish such as waste water systems, rubbish carried by the wind, and recreational litter left behind on beaches (Coe et Rogers, 1997; Ryan et al., 2009). This last category makes up approximately $80 \%$ of the plastic debris that ends up at sea (Cooper et Corcoran, 2010). In lower-income countries, some of the major factors of beach pollution are beach visitors (recreational users and tourists, coastal inhabitants, and recreational activities) due to a high usage of plastics, along with littering behaviour and poor waste management (Jayasiri et al., 2013).

Beach surveys are considered the easiest and most inexpensive way to study large-scale trends in marine debris (Barnes et al., 2009; Ryan et al., 2009). Therefore, as a lower-income country with a long coastline, the island of Madagascar is an attractive subject for such a study. The beaches Ampasindava, Ramena and Baïe de Sakalava were chosen to give a varied geographical coverage of the coastal area in Northern Madagascar near the city Diego-Suarez. The beaches are located in bays, or have a similar geographical outlook, and are referred to as having enclosed or semi-enclosed structures. These structures are beneficial to this study as these types of sites are found to have higher densities of debris than other sites (Coe et al., 1997; Jayasiri et al., 2013).

At the time of the study no research was published in regards to beach debris on Malagasy beaches. Therefore, this study attempts to provide original investigations into the quantity and composition of Malagasy beach debris to determine if there are differences in the type and quantities of litter observed between the beaches, and if this is correlated with usage of the beaches.

\section{MATERIALS AND METHODS}

\subsection{STUDY AREA}

The beach of Ampasindava is located $36 \mathrm{~km}$ west of Diego-Suarez (Antisiranana) on the west coast of Madagascar facing the Mozambique Channel. Ramena is located $18 \mathrm{~km}$ to the northeast of Diego-Suarez, within Baïe Antisiranana, on the east coast of Madagascar, and Baie de Sakalava is on the east coast of Madagascar, facing the Indian Ocean $17.5 \mathrm{~km}$ to the east of Diego-Suarez (Figure 1).

Ampasindava measures a little over $2 \mathrm{~km}$ in length, of which approximately $1.22 \mathrm{~km}$ was studied. Ramena is approximately $3 \mathrm{~km}, 1.27 \mathrm{~km}$ of which was studied, and Baïe de Sakalava measures $1.5 \mathrm{~km}, 1.01 \mathrm{~km}$ of which was studied.

Ramena is located in one of the world's largest bays, Baie Antisiranana, and has an enclosed structure whereas the other beaches have semi-enclosed structures. 


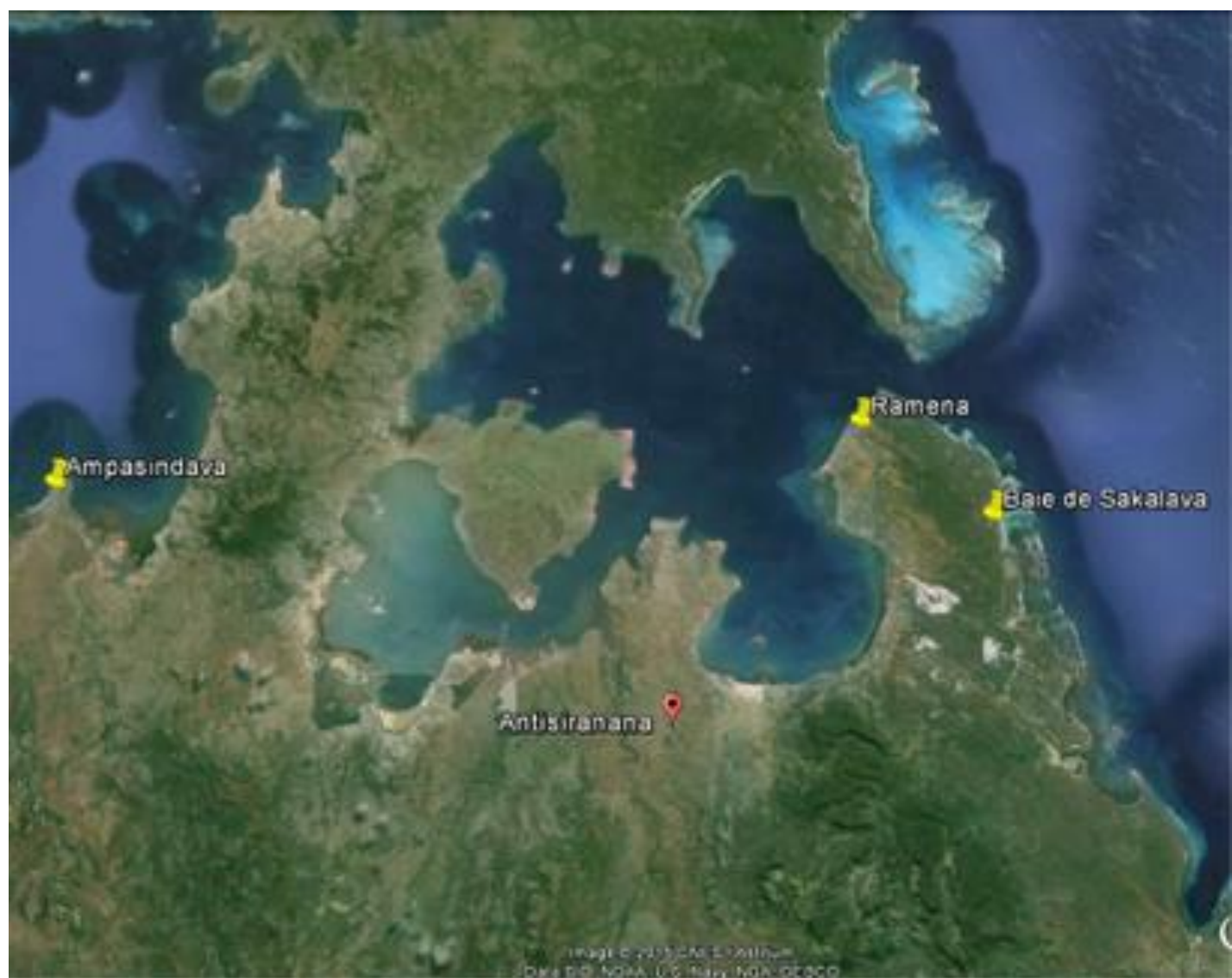

Figure 1: A close-up of the area studied, with a red pin marking Diego-Suarez (Antisiranana) and yellow pins representing the beaches studied.

\subsection{BEACH TRANSECT}

To study the frequency and quantity of macro plastic debris, ten transects were performed each day for three consecutive days at each one of the chosen beaches, with a total of 30 transects per beach and 90 transects in total. Pieces smaller than $1 \mathrm{~cm}^{2}$ were not included. The study was done $+/-2 h$ of low tide, as this gave the longest transects, collecting data using the Beach Litter Survey Methodology and Marine Debris Beach Survey Data Sheet developed by CSIRO.

A GPS was used to record the coordinates at the start point of the transect, then a measuring tape was run perpendicularly to the shoreline into the backshore and at least $2 \mathrm{~m}$ into vegetation where possible. Another GPS reading was noted at the end point of the transect along with the length of the transect, type and color of the substrate, and other beach characteristics, such as beach gradient, physical structure of backshore, beach shape (concave, straight or convex), and direction when facing water was recorded. The transects were located near the beach access point; at Ampasindava and Ramena, transects were performed on both sides of the access points, and at Baïe de Sakalava they were located to the north of the access point. A method of randomisation was used to select the distance between each transect, in order to avoid selection bias by choosing areas of the beach with particularly high or low debris quantities.

At each transect the type and color of all rubbish found within $1 \mathrm{~m}$ to each side of the transect line was noted and classified (see Transect Survey Data Sheet in Appendix). Every transect was also divided into 10 intervals, starting at the seashore with interval 1/10 and ending in the backshore with interval 10/10. The first piece of rubbish encountered within 
each interval was noted as a sample (if there was no debris within an interval this was noted). These samples served to estimate how the debris was distributed about the intervals along the length of the transect.

\subsection{VISUAL OBSERVATIONS}

Visual observations were performed at each beach to compliment the transect survey data. These records included beach usage, proximity to and number of people, proximity to village or other buildings, wind speed and direction, and weather (See Marine Debris Beach Survey in Appendix). Other factors that were recorded include, but are not limited to, personal encounters and cleanliness of the beaches.

\section{RESULTS}

Between the $10^{\text {th }}$ and the $23^{\text {rd }}$ of April 2015, a total of 90 transects were executed on the beaches of Ampasindava, Ramena and Baïe de Sakalava in the Diana Region in Northern Madagascar.

By a method of randomisation, the average distance between the transects performed at Ampasindava was $56 \mathrm{~m}$, while at Ramena this number was $72.6 \mathrm{~m}$, and Baïe de Sakalava was $85.4 \mathrm{~m}$. The average transect length, measured in distance from seashore to backshore, was $39.85 \mathrm{~m}$, at Ampasindava, $43.85 \mathrm{~m}$ at Ramena and $40.10 \mathrm{~m}$ at Baïe de Sakalava.

\subsection{RUBBISH COMPOSITION}

A total of 1216 pieces of beach debris were recorded (Table 1). Of these, $62.34 \%(n=758)$ of the recordings were plastic debris while the sampled plastic had an average estimated size range of $2-8 \mathrm{~cm}^{2}$ (standard error $=$ size class $3.4 \pm 0.283$, Table 3$)$.

Ramena had the highest rubbish count (51.48\% of total) followed by Ampasindava (30.59\%), while Baïe de Sakalava had the lowest amount of debris (17.93\%).

Table 1. Total abundance of beach debris, within various categories, at all beaches individually, and a summarised total.

\begin{tabular}{|l|l|l|l|l|}
\cline { 2 - 5 } \multicolumn{1}{c|}{} & \multicolumn{2}{c|}{ Beach: } \\
\hline Debris type & Ampasindava & Ramena & Baïe de Sakalava & Total \\
\hline Plastic & 257 & 293 & 208 & 758 \\
Cloth & 52 & 15 & 1 & 68 \\
Glass & 13 & 33 & 0 & 46 \\
Metal & 15 & 71 & 2 & 88 \\
Rubber & 0 & 0 & 0 & 0 \\
Foam & 11 & 6 & 4 & 21 \\
Timber & 0 & 0 & 0 & 0 \\
Cigarette butts & 4 & 23 & 1 & 28 \\
Paper & 14 & 171 & 2 & 187 \\
Other & 6 & 14 & 0 & 20 \\
\hline Total & $\mathbf{3 7 2}$ & $\mathbf{6 2 6}$ & $\mathbf{2 1 8}$ & $\mathbf{1 2 1 6}$ \\
\hline
\end{tabular}

Plastic made up 69.1\% of the debris recorded at Ampasindava, 46.8\% at Ramena, $95.4 \%$ at Baïe de Sakalava, and a combined total of $62.3 \%$. 
The combined majority of recorded plastic were hard plastics at $48.02 \%$, followed by filmlike plastics (14.64\%) and plastic string/twine or rope (12.27\%) (see Table 2).

Table 2. Total abundance of various categories of plastic at the individual beaches, including a summarised total.

\begin{tabular}{|l|l|l|l|l|}
\cline { 2 - 5 } \multicolumn{1}{c|}{} & \multicolumn{3}{c|}{ Beach } & \\
\hline Plastic Type & Ampasindava & Ramena & Baïe de Sakalava & Total \\
\hline Hard plastic & 119 & 81 & 164 & 364 \\
Plastic bags & 15 & 60 & 4 & 79 \\
Film-like plastics & 61 & 48 & 2 & 111 \\
Other soft plastics & 22 & 51 & 11 & 84 \\
Plastic packing straps & 3 & 0 & 0 & 3 \\
Net & 3 & 4 & 0 & 7 \\
Fishing line & 10 & 3 & 4 & 17 \\
String/ twine/ rope & 24 & 46 & $\mathbf{2 3}$ & 93 \\
\hline Total & $\mathbf{2 5 7}$ & $\mathbf{2 9 3}$ & $\mathbf{2 0 8}$ & $\mathbf{7 5 8}$ \\
\hline
\end{tabular}

The majority of the sampled plastic ranged from $>1 \mathrm{~cm}^{2}$ to $2 \mathrm{~cm}^{2}$ at Ampasindava, from $4-8 \mathrm{~cm}^{2}$ at Ramena, and from $>1 \mathrm{~cm}^{2}$ to $4 \mathrm{~cm}^{2}$ at Baïe de Sakalava (see Table 3). Samples smaller than $1 \mathrm{~cm}^{2}$ were not recorded.

Table 3. Sizes of sampled plastic debris, collected randomly at 10 intervals within each transect length, classified as size classes 1-6.

\begin{tabular}{|c|c|c|c|c|}
\hline \multirow[b]{2}{*}{ Size class } & \multicolumn{3}{|c|}{ Beach } & \multirow[b]{2}{*}{ Total } \\
\hline & Ampasindava & Ramena & Baïe de Sakalava & \\
\hline $1=1 \mathrm{~cm}^{2}$ & $21.25 \%$ & $1.30 \%$ & $10.94 \%$ & $\mathbf{1 1 . 3 1 \%}$ \\
\hline $2=1-2 \mathrm{~cm}^{2}$ & $23.75 \%$ & $18.18 \%$ & $26.56 \%$ & $22.62 \%$ \\
\hline $3=2-4 \mathrm{~cm}^{2}$ & $18.75 \%$ & $15.58 \%$ & $26.56 \%$ & $19.91 \%$ \\
\hline $4=4-8 \mathrm{~cm}^{2}$ & $15.00 \%$ & $28.57 \%$ & $18.75 \%$ & $20.81 \%$ \\
\hline $5=8-16 \mathrm{~cm}^{2}$ & $8.75 \%$ & $18.18 \%$ & $3.13 \%$ & $10.41 \%$ \\
\hline $6>16 \mathrm{~cm}^{2}$ & $12.50 \%$ & $18.18 \%$ & $14.06 \%$ & $14.93 \%$ \\
\hline
\end{tabular}

\subsection{RUBBISH PER SQUARE METRE}

The standard deviations for the average rubbish per $\mathrm{m}^{2}$ represent the variance in transect lengths. This variance was due to interruptions by seawalls, buildings, etc.

The average rubbish distribution at Ampasindava was 0.157 pieces per $\mathrm{m}^{2}, 0.23$ pieces per $\mathrm{m}^{2}$ at Ramena, and 0.088 pieces per $\mathrm{m}^{2}$ at Baïe de Sakalava, totalling an average of 0.158 pieces per $\mathrm{m}^{2}$ (Figure 2).

The average distribution of plastic was 0.109 pieces per $\mathrm{m}^{2}$ at Ampasindava, 0.106 pieces per $\mathrm{m}^{2}$ at Ramena, and 0.084 pieces per $\mathrm{m}^{2}$ at Baïe de Sakalava, totalling an average of 0.1 pieces per $\mathrm{m}^{2}$ (Figure 2). 


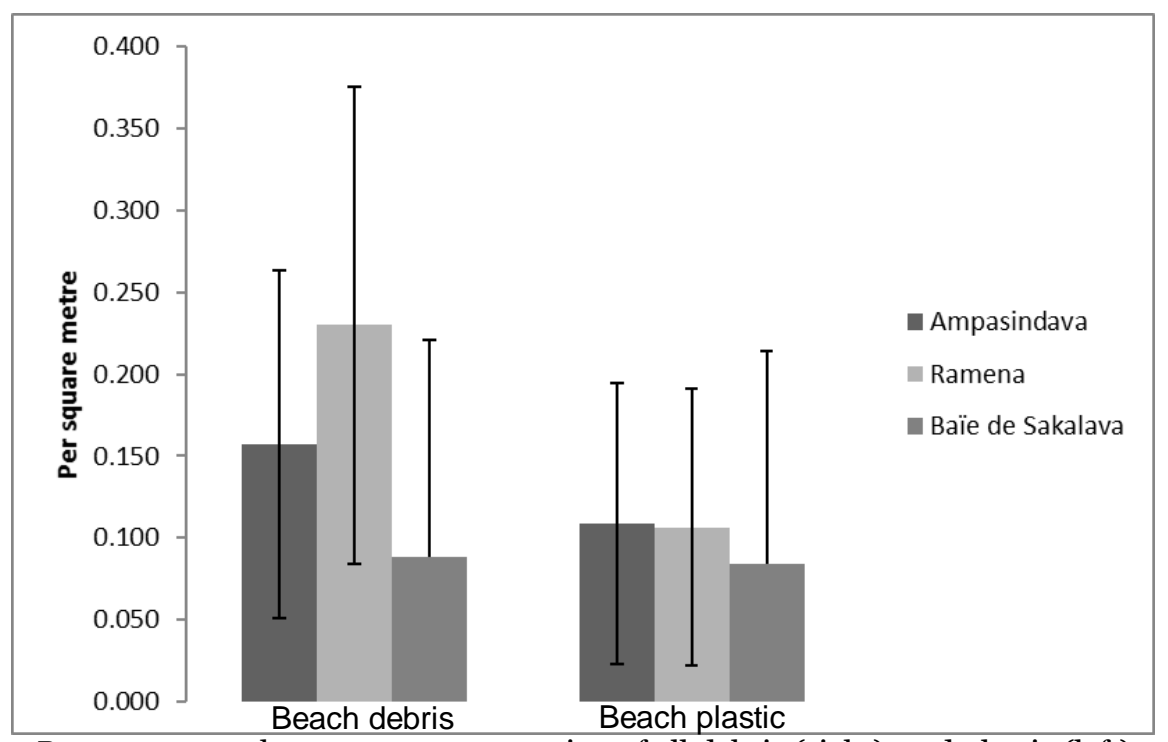

Figure 2: Bars represent the average concentration of all debris (right), and plastic (left) per $\mathrm{m}^{2}$ for each individual beach. The error bars represent the standard deviation of the concentration at each transect on each beach.

\subsection{DISTRIBUTION OF DEBRIS WITHIN INTERVALS}

The sampled debris, recorded at each transect interval in distance from seashore to backshore, had a summarized peak (7.4\% of debris) at interval 9/10, corresponding to the wrack-line, the area just above mean high tide where debris is deposited. This was closely followed by interval 10/10 (7.1\%), at the backshore (Figure 3). There is also a slight peak near interval $1 / 10$ (2.7\%), which corresponds to the seashore.

Ampasindava had an overall peak (8.33\%) at the end of the transect length and into the backshore at interval 10/10. Ramena had two peaks; one peak appeared at interval 1/10 at the seashore (6\%) and another one at interval 9/10 at the wrack-line (9\%). Baïe de Sakalava had a peak (6\%) at interval 9/10, corresponding with the wrack-line (Figure 3).

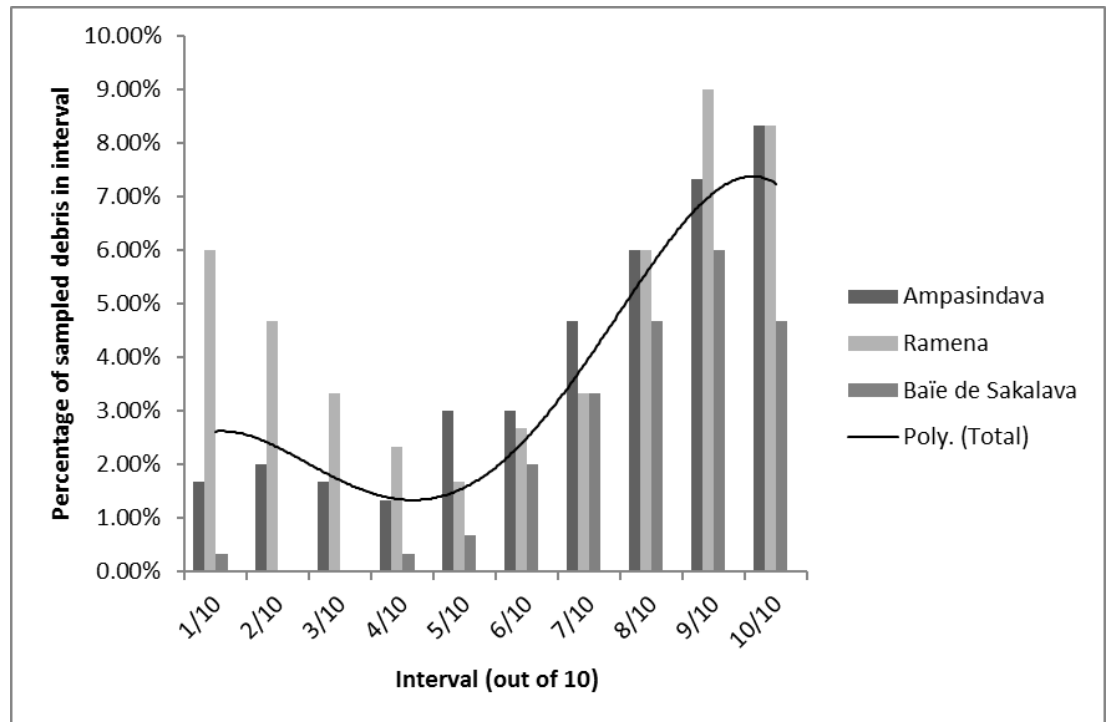

Figure 2: Proportion of total debris located at various 1/10th intervals beachwise. $\mathrm{X}$-axis represents each of the 10 intervals in distance from the seashore (1/10th) to the backshore (10/10th), making up the total length of the transect. Y-axis represents the percentage of sampled rubbish located within each interval. The trendline, Poly. (Total), displays the average distribution of all three beaches combined. 
The sample plastic had a summarised peak at the backshore (24.4\% of sampled plastic), interval 10/10, followed by interval 9/10 (23.5\%). The plastic at Ampasindava (23.8\% of sample) and Ramena (28.8\%) was mostly located at the backshore, interval 10/10. There was a slight variance at Baïe de Sakalava where the majority of plastic was recorded at the wrackline (26.6\%), interval 9/10 (Figure 4).

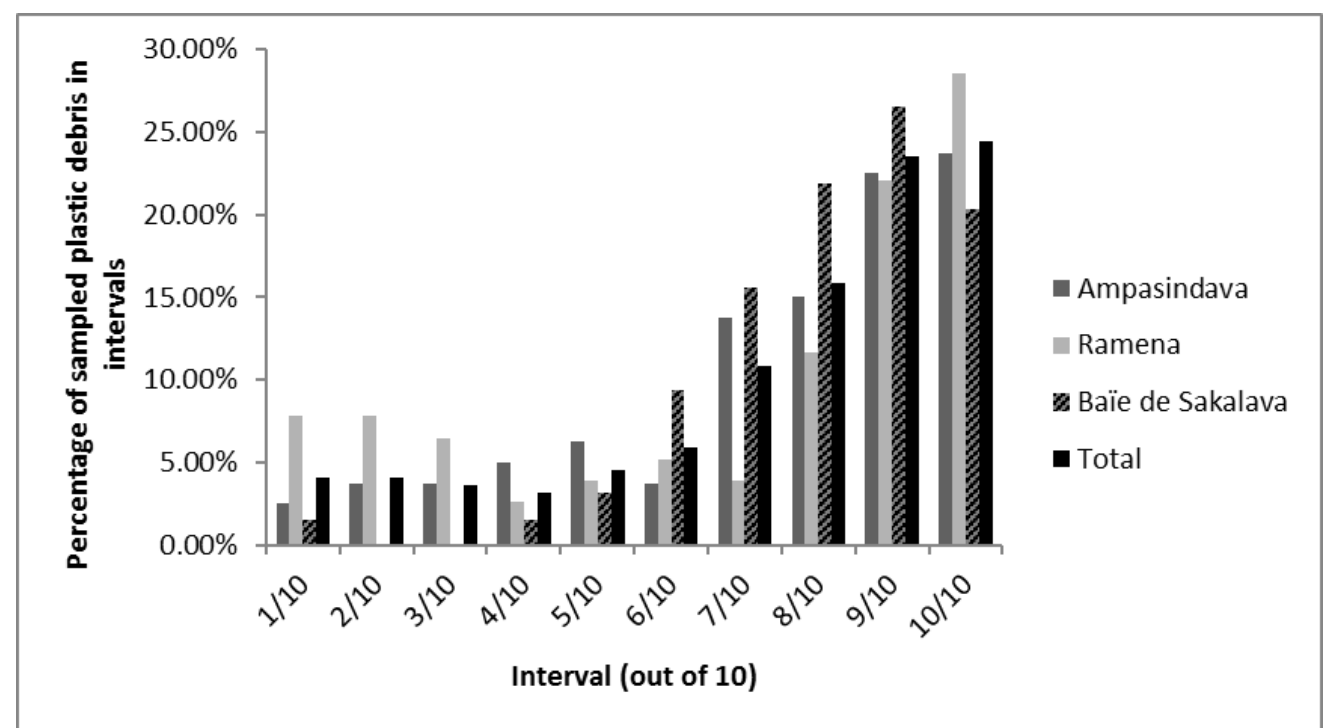

Figure 3: Proportion of sampled plastic debris distributed along the transect length at intervals 1-10, where $1 / 10^{\text {th }}$ is the seashore and $10 / 10^{\text {th }}$ is the backshore.

\subsection{COLOR DISTRIBUTION}

The most frequently recorded color of plastic was white at $30.08 \%$, followed by blue/purple (26.12\%), and clear/translucent (16.36\%). The remaining $27.44 \%$ of the sampled plastics were other colors (Figure 5).

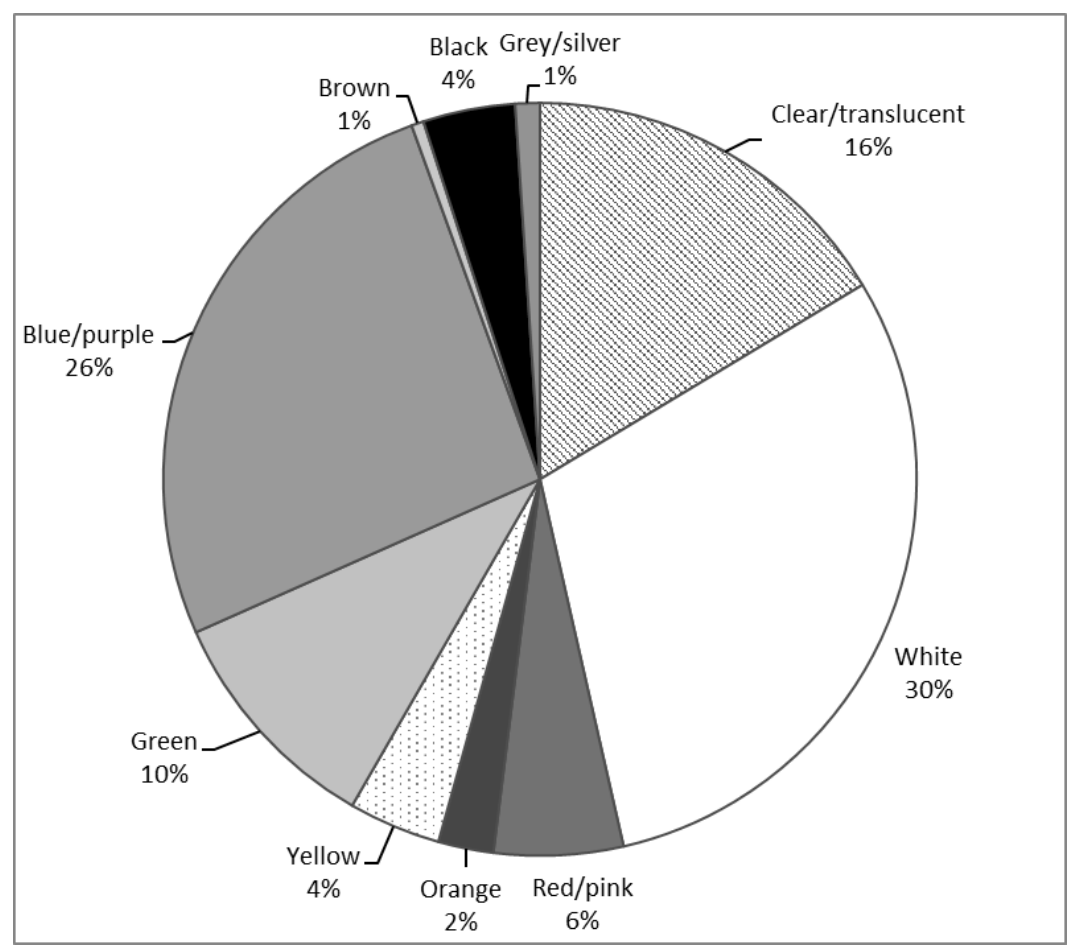

Figure 4: Color distribution of all recorded pieces of plastic in total of all three beaches combined. 


\subsection{A NOTE ON BEACH CLEAN-UPS}

A beach clean-up was reported to have been executed by the locals at Ampasindava the $8^{\text {th }}$ of March 2015 and an annual clean-up at Baïe de Sakalava was scheduled for the first week of May 2015 by a local kite surfing organization. No organized beach clean-up effort had been performed at Ramena over the past two to three years (according to people in the area). It is likely that these clean-ups had a decreasing effect on the debris quantity. According to Derraik (2002), and Garrity and Levings (1993), the beaches cleaned in Panama regained approximately half of their original debris quantity after three months. It is therefore likely that the impact of these clean-up activities on the cleanliness of the beaches, and therefore the results of this study, is smaller than first expected.

\section{DISCUSSION}

\subsection{LOCATION}

The distribution of plastic debris varied depending on the beach (Figure 3) and seemed to correspond with the usage by visitors. In general, the majority of rubbish had a peak closest to the shoreline, at the $1 / 10^{\text {th }}$ interval, with a gradual build up towards another peak at the debris line or beginning of backshore, the $9 / 10^{\text {th }}$ interval. Overall, the general trend for the debris recorded at the backshore seemed to originate from the nearby inhabited areas due to poor or lacking rubbish disposal sites and infrastructure, unconscious or conscious dumping, and dispersal by wind (personal observations, Gjerdseth). These findings correspond to others' findings that plastic rubbish globally increases due to lack of recovery, recycling and disposal sites (Moore et al., 2008; Reisser et al., 2013). At Ampasindava, a few locals $(n=6)$ stated that a common practice of waste management was to make a pile of it at the edge of their property to be left or burned. These piles were then vulnerable to dispersal by terrestrial winds, carrying a portion to the beach, which is a likely reason why the concentration of debris was higher at the backshore.

There was minimal difference in debris distribution at various intervals at Ramena (Figure 3); at high tide all debris was semi- or fully submerged in water and some was left behind at the wrack-line as the water retracted and some carried out with the tide. Restaurants were also observed sweeping their rubbish down to the tideline in the mornings, leaving it there for the tide. Beachgoers were observed leaving rubbish behind, and on two occasions the author observed individuals dumping the contents of rubbish bins directly into the ocean (personal observations, Gjerdseth). These factors all contribute to the quantity and distribution of debris at the beach.

The majority of rubbish noted at the transect intervals ranged from $2 \mathrm{~cm}^{2}$ to $8 \mathrm{~cm}^{2}$ (Table 3), which supports the claim that smaller pieces of rubbish are more easily dispersed by the wind, as described by Moore et al. (2008) with regard to shopping bags that become airborne and end up in distant waterways and seas.

\subsection{COMPOSITION}

Plastic debris accounted for $62 \%$ of the total recorded debris was categorised as plastic, a trend that corresponds with Derraik (2002) who found that the majority of marine litter on a global scale was made up of plastic. Hard plastics made up $48.02 \%$ of the total plastic recorded, a proportion that correlates to findings by Moore et al. (2001) who surveyed beaches in California and found hard plastics among the most abundant. Other frequent rubbish categories include film-like plastics and fishing equipment, which corresponds to findings by 
the Marine Conservation Society (2014) who report plastic pieces, fishing line, and wrappers as the most frequent plastic items found in their beach clean-ups in England, Scotland, Northern Ireland, and Wales.

Of the plastic found on Ampasindava, Ramena, and Baïe de Sakalava 72.56\% were classified as clear/translucent, white, and blue/purple (Figure 4). This percentage corresponds to Reisser et al. (2013) who reported that the majority of plastic (93\%) found in their study was white, transparent or blue. These results also coincide with reports on marine plastics, which state that the plastic debris is affected by the feeding ecology and ingestion in various ecosystems, and that some species of birds are known to select foods using color vision, or choose foods of specific shapes and colors (Derraik, 2002; Reisser et al., 2013; Shaw and Day, 1994). It is therefore likely that the percentage of plastic colors such as red/pink, orange, yellow and green are lower due to a higher probability of being eaten by animals because of their resemblance to certain foods.

Another factor affecting the color distribution of the debris is that some items are normally produced in certain colors. Items such as fishing gear often come in colors that camouflage the gear in the environment. Of the plastics recorded in this study, fishing line (along with string and rope) made up $15.44 \%$, with the majority being colored blue, green or clear. The colors could also be bleached due to weathering, especially if the material has been exposed over a longer time period.

Hard plastic and plastic bags made up the majority of the plastic rubbish found at Ramena (48.1\%). This category includes items such as plastic bottles, cups and plates, likely left behind by beach users (personal observations, Gjerdseth). This agrees with observations by Jayasiri et al. (2013) with regard to plastics usage and littering behaviour of beach users in developing countries.

At Baie de Sakalava there was some debris recorded near a seawall by the access point that appeared to have been recently disposed of, but the majority of litter seemed weathered; pieces of debris had bleached color, more porous structure, were fragmented pieces with smoother edges, etc. This lack of fresh rubbish might be due to the annual beach clean-ups; the weathered plastic might have been brought in by the ocean at high tide and left at the wrackline. Further research is needed to support this claim.

\subsection{QUANTITY}

The highest quantity of rubbish, in total and quantity per $\mathrm{m}^{2}$, was observed at Ramena, while the lowest quantity was at Baïe de Sakalava (Figure 2). Baïe de Sakalava had the lowest beach usage, had steep commute fares due to limited access, and had few permanent inhabitants in close proximity to the beach (personal observations, Gjerdseth). With these variables, the low quantity of rubbish per $\mathrm{m}^{2}$ was expected. Barnes (2005) found that accumulation rates of marine debris varied depending on the beach usage and proximity to urban settlements, and other factors such as wind, ocean currents and region. Ramena had higher settlements and number of beach visitors than the other beaches, which is likely to have impacted debris count. This is supported by Jayasiri et al. (2013) who found number of visitors, usage and proximity to city centre to be some of the most important contributors to debris quantity and distribution. The high quantity of debris at Ramena may also be affected by the variance in geography between the beaches. Ramena is located within Antsiranana Bay and has an enclosed structure, whereas Ampasindava and Baïe de Sakalava are less confined and have semi-enclosed structures. This variance in geography is likely to have affected the rubbish concentration on the beaches; it might be higher in Ramena due to the accumulation effect in bays (Coe et al., 1997; Jayasiri et al., 2013). 
In their 2014 beach clean-up report, the Marine Conservation Society (2004) found 2,457 pieces of rubbish per kilometre, equivalent to 6.04 pieces per $\mathrm{m}^{2}$, with a majority stemming from "public/general dumping" including items such as plastic bags, bottles and cans, food containers, party poppers, and balloons. Allsopp et al. (2006) reported that the highest quantities of rubbish per $\mathrm{m}^{2}$ of shoreline were found in Indonesia with up to 29.1 pieces per metre of shoreline, equivalent to 846.81 pieces per $\mathrm{m}^{2}$, as well as Sicily with up to 231 pieces per metre, equivalent to 53,36 pieces per $\mathrm{m}^{2}$. Barnes and Milner (2005) reported an average of 1.14 debris items per metre, or 1.3 per $\mathrm{m}^{2}$, in their research using samples of shore stranded debris from 16 locations, ranging from Antarctica (via the Faeroe Islands, Caribbean, Canary Islands, South- and Mid- Atlantic, UK, and Iceland) to the Arctic. The findings in this study (0.158 pieces per $\mathrm{m}^{2}$ ) are low in comparison to other beaches surveyed in comparable studies (Figure 2). The average of 0.1 pieces of plastics per $\mathrm{m}^{2}$ recorded in this study are low in comparison to findings by Jayasiri et al. (2013) who noted an average of 68.83 items of plastic per $\mathrm{m}^{2}$ in their beach study. The reason for these relatively low concentrations on the beaches surveyed might be due to a smaller number of beach visitors and coastal inhabitants, although further research is needed.

A situation was identified that may affect the data gathered. A few individuals $(n=5)$ encountered at Ramena and Ampasindava stated that the concentration of rubbish was high due to a recent Easter celebration. They claimed that the beach had received a high number of visitors for the holiday, many of whom had left behind their rubbish after the festivities (Easter Monday was the $6^{\text {th }}$ of April 2015). This may have affected the debris recorded in this study.

\section{CONCLUSION}

Based on the data collected in this study, there was a positive correlation between the frequency and quantity of usage of a beach and the amount of debris recorded.

The majority of debris recorded was plastic debris of clear/translucent, white, and blue/purple color, which is similar to other reports on marine debris.

There is a high probability that the debris will enter the ocean, as a majority of debris was located close to the seashore or at the wrack-line, implying a possibility of being transported with the tides.

A major contributor to the quantity of man-made debris was poor or lacking disposal opportunities and/or practices. Addressing this deficiency could have a significant local impact. Since the majority of the plastic and man-made debris recorded originated from landbased sources, awareness of the issues surrounding plastic pollution and its consequences could help reduce the quantity of debris ending up on the beaches. On a larger scale, given the increased usage of plastic, its lifecycle should be analysed more thoroughly. A larger scale policy that targets non-biodegradable material, such as plastics, with a focus on recycling and reduction of excessive use, is likely to have a positive impact on the reduction of beach and marine plastics.

\section{ACKNOWLEDGEMENTS}

I would like to thank Barry Ferguson, Ted Duckett, Jim Hansen, and McGordon Ranaivo Arivelo for valuable advice, information, and for pointing me in the right directions. 


\section{REFERENCES}

Allsopp, M., Walters, A., Santillo, D., \& Johnston, P. (2006). Plastic Debris in the World's Oceans. Greenpeace.

Andrady, A. (1990). Environmental Degradation of Plastics under Land and Marine Exposure Conditions. In R. a. Shomura (Ed.), Proceedings of the Second International Conference on Marine Debris, (pp. 848-869). Washington, DC. : U.S. Department of Commerce.

Barnes, D. (2005). Remote islands revealed rapid rise of Southern Hemisphere sea debris. The Scientific World , 5, 915-921.

Barnes, D., \& Milner, P. (2005). Drifting plastic and its consequences for sessile organism dispersal in the Atlantic Ocean. Marine Biology , 146 (4), 815-825.

Barnes, D., \& Milner, P. (2005). Drifting plastic and its consequences for sessile organism dispersal in the Atlantic Ocean. Marine Biology , 146 (4), 815-825.

Box, C., \& Eriksen, M. (2014). How to Carry Out a Beach Transect: Plastic Beach Project. 5 Gyres.

Coe, J., Andersson, S., \& Rogers, D. (1997). Marine debris in the Caribbean region. Coe, J.M.; Rogers, D.B. (Eds.), Marine Debris: Sources, Impact and Solutions , 25-34.

Cooper, D. A., \& Corcoran, P. L. (2010). Effects of mechanical and chemical processes on the degradation of plastic beach debris on the island of Kauai, Hawaii. Marine Pollution Bulletin , 6o, 650-654.

Cooperative Institute for Meteorological Satellite Studies. (n.d.). Retrieved May 5, 2015, from Cooperative Institute for Meteorological Satellite Studies: Cimss.ssec.wisc.edu

Derraik, J. (2002). The pollution of the marine environment by plastic debris: a review. Marine Pollution Bulletin , 44, 842-852.

Goldstein, M. C., Titmus, A. J., \& Ford, M. (2013). Scales of Spatial Heterogeneity of Plastic Marine Debris in the Northeast Pacific Ocean. PLoS ONE , 8 (11).

Gregory, M. R. (2009). Review: Environmental implications of plastic debris in marine settings-entanglement, ingestion, smothering, hangers-on, hitch-hiking and alien invasions. Philosophical Transactions of the Royal Society B , 364, 2013-2025.

Jayasiri, H., Purushothaman, C., \& Vennila, A. (2013). Quantitative analysis of plastic debris on recreational beaches in Mumbai, India. Marine Pollution Bulletin, 77, 107-112.

Laist, D. W. (1987). Overview of the biological effects of lost and discarded plastic debris in the marine environment. Marine Pollution Bulletin , 18 (6), 319-326.

Marine Conservation Society. (2014). Great British Beach Clean 2014 Report. Marine Conservation Society.

Moore, C. (2008). Synthetic polymers in the marine environment: A rapidly increasing, long-term threat. Environmental Research , 108 (2), 131-139.

Moore, S. L., Gregorio, D., Carreon, M., Weisberg, S., \& Meecaster, M. (2001). Composition and Distribution of Beach Debris in Orange County, California. Marine Pollution Bulletin , 42 (3), 241-245. 
Opfer, S., Arthur, C., \& Lippiatt, S. (2012). NOAA Marine Debris Shoreline Survey Field Guide. NOAA Marine Debris Program .

Reisser, J., Shaw, J., Wilcox, C., Hardesty, B. D., Proietti, M., Thums, M., et al. (2013). Marine Plastic Pollution in Waters around Australia: Characteristics, Concentrations, and Pathways. PLOS ONE .

Rios, L., \& Moore, C. (2007). Persistent organic pollutants carried by synthetic polymers in the ocean environment. Marine Pollution Bulletin , 54 (8), 1230-1237.

Ryan, P., Moore, C., Franeker, J., \& Moloney, C. (2009). Monitoring the abundance of plastic debris in the marine environment. Philosophical Transactions of the Royal Society $B$ (2009): Biological Sciences , 364 (1526), 1999-2012.

Thompson, R., Olsen, Y., Mitchell, R., Davis, A., Rowland, S., John, A., et al. (2004). Lost at sea: where is all the plastic? Science , 304 (838).

Zettler, E. R., Mincer, T. J., \& Amaral-Zettler, L. A. (2013). Life in the "Plastisphere": Microbial Communities on Plastic Marine Debris. Environmental Science \& Technology , 47 (13), 7137-46. 


\section{APPENDIX}

\section{METHOD BY CSIRO}

\section{MARINE DEBRIS BEACH SURVEY DATA SHEET}

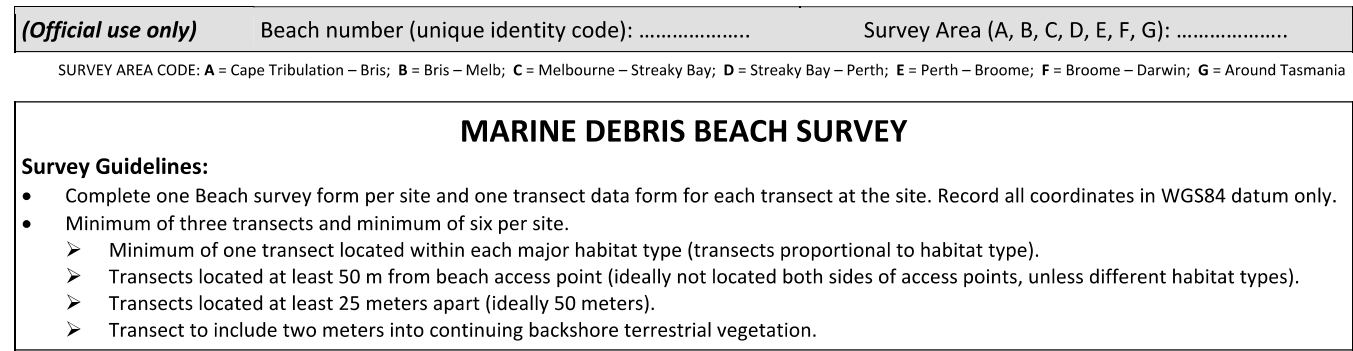

\begin{tabular}{|c|c|c|}
\hline \multicolumn{3}{|l|}{ SURVEYOR DETAILS } \\
\hline Organisation: & & Organisation responsible for survey. \\
\hline Surveyor name: & & Name of chief surveyor. \\
\hline Contact number: & & Contact number for surveyor. \\
\hline Access point location: & Latitude: & $\begin{array}{l}\text { Latitude and longitude of access point where you enter the } \\
\text { beach (dd.dddd). }\end{array}$ \\
\hline GPS accuracy: & & Accuracy (meters) of GPS at time of reading. \\
\hline
\end{tabular}

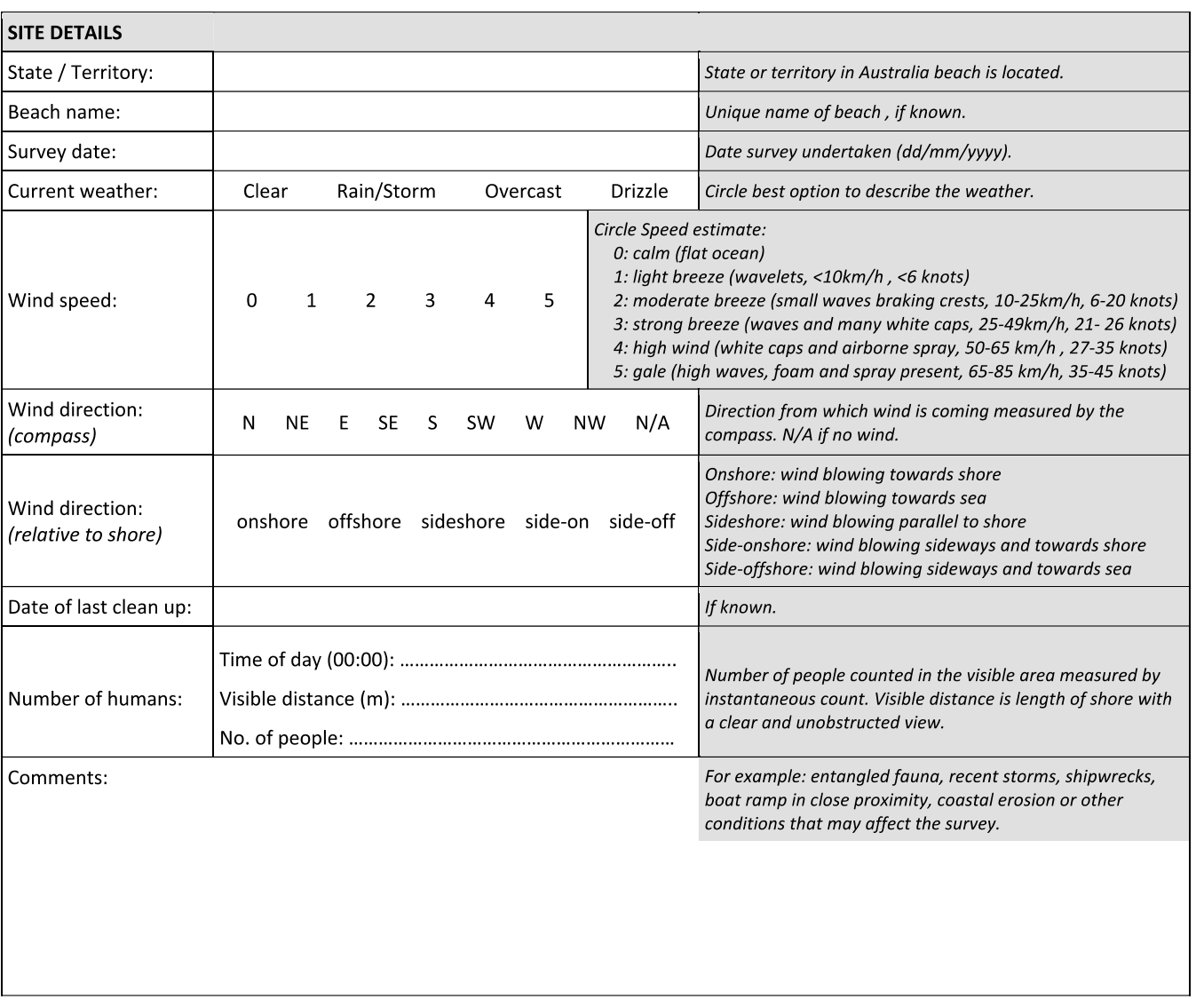

Page | 1 
TRANSECT DATA SHEET

Transect Data

\begin{tabular}{|l|l|l|l|}
\hline Beach Name: & Name of surveyor(s): & \\
\hline Transect Number: & & No. of surveyor(s): & \\
\hline Transect width $(\mathrm{m}):$ & Transect Number _ of \\
\hline
\end{tabular}

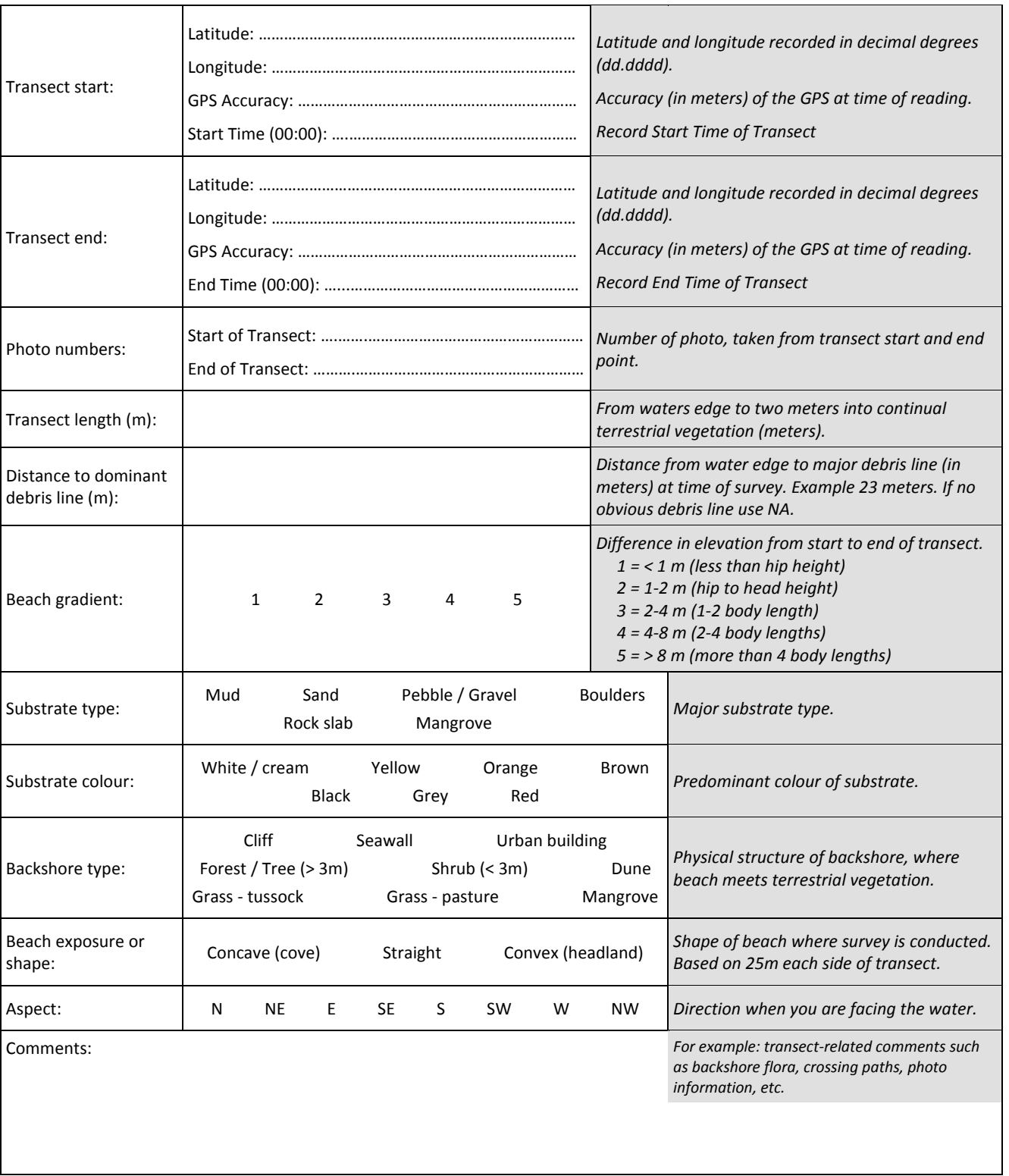

Page | 3 
TRANSECT SURVEY DATA SHEET

\begin{tabular}{|c|c|c|c|c|c|c|c|c|c|c|c|c|c|c|c|}
\hline \multicolumn{12}{|c|}{$\begin{array}{l}\text { Transect debris (type and colour): Record one mark (e.g. IIII) for each piece of fubbish larger than } 1 \mathrm{~cm}^{2} \text { in size, within } 1 \text { metre each side of } \\
\text { the transect line. If you find items other than those listed, add details to bottom of table. }\end{array}$} & \multicolumn{4}{|c|}{$\begin{array}{l}\text { Size classes: Sample debris type and size } \\
\text { class at ten intervals along each transect. }\end{array}$} \\
\hline & \multirow[b]{2}{*}{ Rubbish Type } & & & & & Colou & & & & & & \multirow{4}{*}{ 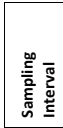 } & \multirow{4}{*}{ 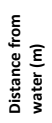 } & \multirow{4}{*}{ 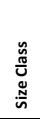 } & \multirow{4}{*}{$\frac{\bar{z}}{\frac{\partial}{2}}$} \\
\hline & & $\begin{array}{l}\text { clear I } \\
\text { trassuluent }\end{array}$ & White & Red/ pink & Orange & Yellow & Green & Blue / purple & Brown & Black & Grey / silver & & & & \\
\hline & Hard plastic & & & & & & & & & & & & & & \\
\hline & Plastic bags & & & & & & & & & & & & & & \\
\hline & $\begin{array}{l}\text { FFllillike plasticic (fladd } \\
\text { whra and chip bags) }\end{array}$ & & & & & & & & & & & & & & \\
\hline & Other soft plastics & & & & & & & & & & & 2 & & & \\
\hline & Plastic packing straps & & & & & & & & & & & & & & \\
\hline & Net (estimate size) & & & & & & & & & & & $\left.\right|^{3}$ & & & \\
\hline & Fishing line & & & & & & & & & & & 4 & & & \\
\hline $\bar{a}$ & $\begin{array}{l}\text { Plastic (string, twine, } \\
\text { rope) }\end{array}$ & & & & & & & & & & & & & & \\
\hline \multirow{3}{*}{ 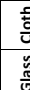 } & $\begin{array}{l}\text { Non-plastic (string, } \\
\text { twine, rope) }\end{array}$ & & & & & & & & & & & & & & \\
\hline & & & & & & & & & & & & & & & \\
\hline & Glass & & & & & & & & & & & & & & \\
\hline \multirow{2}{*}{$\overline{\mathrm{g}}$} & Fish hook & & & & & & & & & & & 8 & & & \\
\hline & $\begin{array}{l}\text { Metal (hard) } \\
\text { Metal (soft, tinfoil) }\end{array}$ & & & & & & & & & & & |9 & & & \\
\hline \multirow{2}{*}{ 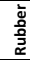 } & Balloon & & & & & & & & & & & & & & \\
\hline & Other rubber items & & & & & & & & & & & 10 & & & \\
\hline & 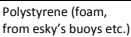 & & & & & & & & & & & \multirow{2}{*}{\multicolumn{4}{|c|}{\begin{tabular}{|l} 
1. Divide the total transect length by 10 to \\
determinin sampling interval e.g. if \\
transect is $35 \mathrm{~m}$, interval $=3.5 \mathrm{~m}$.
\end{tabular}}} \\
\hline 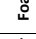 & Other foam & & & & & & & & & & & & & & \\
\hline & $\begin{array}{l}\text { Wood (posts, beans, } \\
\text { ship nuls) }\end{array}$ & & & & & & & & & & & \multirow{3}{*}{\multicolumn{4}{|c|}{$\begin{array}{l}\text { 2. At each interval record the type and size } \\
\text { of the first piece of rubbish encountered. If } \\
\text { no rubbish is detected within the interval } \\
\text { draw a line through the box and continue }\end{array}$}} \\
\hline \multirow{2}{*}{ 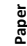 } & Cigarette butts & & & & & & & & & & & & & & \\
\hline & Paper & & & & & & & & & & & & & & \\
\hline & & & & & & & & & & & & \multirow{4}{*}{\multicolumn{4}{|c|}{ 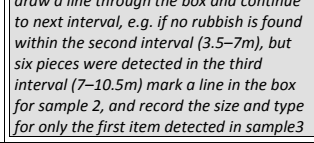 }} \\
\hline 离 & & & & & & & & & & & & & & & \\
\hline & & & & & & & & & & & & & & & \\
\hline & & & & & & & & & & & & & & & \\
\hline
\end{tabular}

Page | 4 